University of New Hampshire

University of New Hampshire Scholars' Repository

8-14-2008

\title{
An academic-community outreach partnership: building relationships and capacity to address childhood lead poisoning.
}

Nancy Serrell, MALS; Rosemary M. Caron, PhD, MPH; Bethany Fleishman, BS; and Emily D. Robbins, BA; National Institute of Environmental Health Sciences, The Johns Hopkins University Press

Follow this and additional works at: https://scholars.unh.edu/mrg

\section{Recommended Citation}

Nancy Serrell, MALS; Rosemary M. Caron, PhD, MPH; Bethany Fleishman, BS; and Emily D. Robbins, BA; National Institute of Environmental Health Sciences, The Johns Hopkins University Press, "An academiccommunity outreach partnership: building relationships and capacity to address childhood lead poisoning." (2008). Manchester Research Group. 11.

https://scholars.unh.edu/mrg/11

This Text is brought to you for free and open access by the UNH Community Projects at University of New Hampshire Scholars' Repository. It has been accepted for inclusion in Manchester Research Group by an authorized administrator of University of New Hampshire Scholars' Repository. For more information, please contact Scholarly.Communication@unh.edu. 


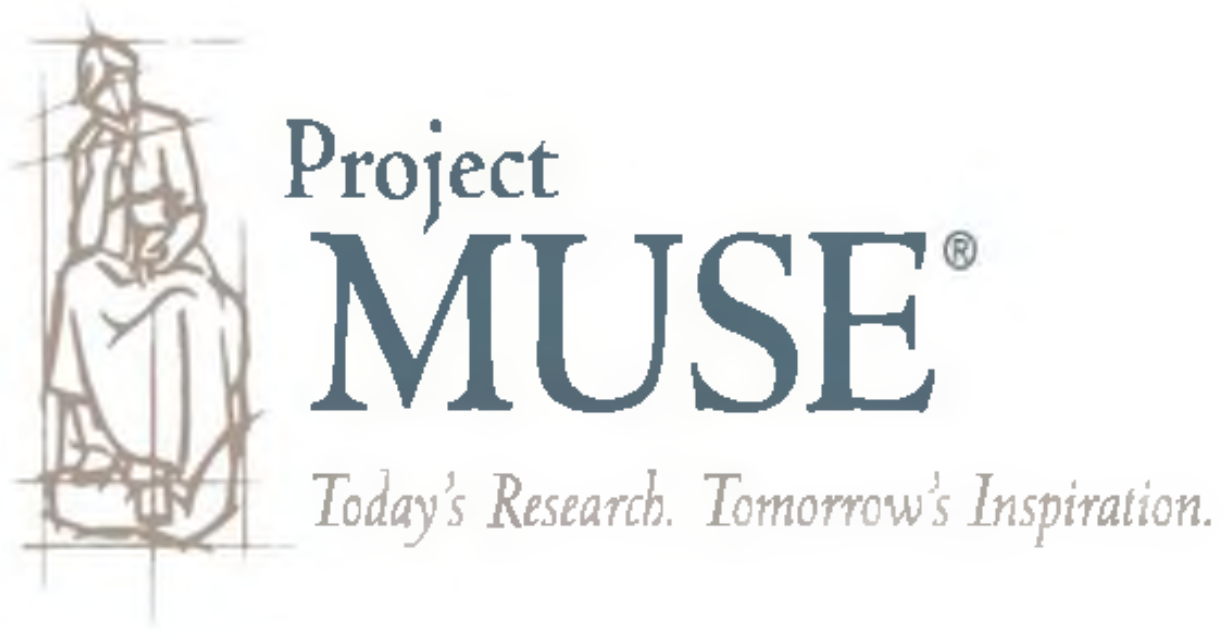




\title{
An Academic-Community Outreach Partnership: Building Relationships and Capacity to Address Childhood Lead Poisoning
}

\author{
Nancy Serrell, MALS ${ }^{1}$, Rosemary M. Caron, PhD, MPH², Bethany Fleishman, BS ${ }^{1}$, and Emily D. Robbins, BA ${ }^{1}$ \\ (1) Dartmouth College, Dartmouth Toxic Metals Research Program; (2) University of New Hampshire, Department of Health Management and Policy, Master of Public \\ Health Program \\ Submitted 10 March 2008; revised 1 August 2008, accepted 14 August 2008. Supported by NIH Grant Number P42 ES007373 from the National Institute of Environmental \\ Health Sciences.
}

Abstract

Background: Although academic institutions are rich resources for improving public health, academic partnerships with community organizations can be challenging. We describe a successful academic-community partnership composed of the Dartmouth Toxic Metals Research Program, the Manchester (New Hampshire) Health Department, and the Greater Manchester Partners Against Lead Poisoning (GMPALP).

Objective: Partners collaborated to translate science and best practices into social action and policy change to address childhood lead poisoning.

Methods: Using the evolution of a childhood lead poisoning prevention initiative, we discuss how an academic-community relationship can be created and sustained.
Lessons Learned: Our experience demonstrates that broadbased partnerships are enhanced by the attributes of community-based participatory research (CBPR). We observe that engaging in community collaborations that are not driven by research eliminates potential conflicts for academic and community partners.

Conclusion: We identify four core values, namely, (1) adaptability, (2) consistency, (3) shared authority, and (4) trust, as being constructive when working in such partnerships.

\section{Keywords}

Childhood lead screening, academic-community partnerships, community outreach, quality improvement, Superfund Basic Research Program
$\mathrm{M}$ anchester, New Hampshire, represents an urban microcosm of the childhood lead poisoning problem. With a total population of approximately 110,000 residents, the city represents $10 \%$ of the state's population and one third of all childhood lead poisoning cases. Owing to the prevalence of pre-1950 housing in Manchester, the city is designated one of the highest risk regions of the state. As a result, the Centers for Disease Control and Prevention recommend that all 1-and 2-year-old children residing in Manchester be tested for lead paint exposure. ${ }^{1-3}$

In 1997, the Manchester Health Department, which has several decades' worth of experience inspecting homes and buildings for lead, issuing lead abatement orders, and providing case management and education on lead hazards, formed a local, broad-based, community consortium to address this persistent public health issue. The Greater Manchester Partners Against Lead Poisoning (GMPALP) is composed of representatives from low-income housing organizations, a minority health coalition, clinicians, the state Childhood Lead Poisoning Prevention Program, rental property owners, and other diverse community members committed to addressing the issue of lead poisoning in the Manchester area.

In 2000, a child in Manchester died of lead poisoning. Pediatric fatalities from lead poisoning are rare, and this was the first reported death of a child from lead poisoning in the United States since 1990. ${ }^{4}$ This tragedy underscored the need for more resources, more expertise, and more community support. In response, the Manchester Health Department 
invited the Dartmouth Toxic Metals Research Program's Community Outreach Group to join the GMPALP.

The purpose of this article is to describe the evolution and endeavors of this academic-community collaboration. Together, the Dartmouth Group, the Manchester Health Department, and the GMPALP collaborated in a "Call to Action" community meeting and other efforts to foster new partnerships, propose "action steps," and coordinate statewide lead poisoning prevention initiatives. Their actions contributed to increased funding and an amended New Hampshire law that helps to protect children before they become lead poisoned. ${ }^{5}$ Each of these initiatives was community driven and was informed by evidence-based knowledge that incorporated academic and community perspectives. Collectively, these initiatives represent the values and approach of CBPR, "a systematic effort to incorporate community participation and decision making, local theories of etiology and change, and community practices." The authors credit this approach for the outcomes of this collaboration, many of which parallel the benefits of CBPR, such as increased trust between academic participants and community and the translation of sciencebased information into policy. We present this 8-year collaboration in broad strokes, using the evolution of a Childhood Lead Screening Initiative as a case study, to describe how a collaborative academic-community partnership can be created and sustained, and how it can build capacity to address a local public health issue.

\section{CORE VALUES FOR AN ACADEMIC-COMMUNITY OUTREACH PARTNERSHIP}

The National Institute of Environmental Health Sciences provides a way to link scientific research groups to communities affected by environmental hazards through the Community Outreach component of its Superfund Basic Research Program (SBRP). The SBRP engages in a range of activities, such as sharing SBRP research findings with communities affected by hazardous waste sites, incorporating community perspectives into remediation processes, creating tools for translating SBRP science, and providing leadership training for community groups. Specifically, the community outreach component of these grants support nonresearch activities, such as serving as a scientific resource for communities, improving community awareness and understanding of environmental health issues, and establishing collaborative projects among communities, investigators, and other colleagues to address environmental problems. ${ }^{7}$ The academic-community collaboration described herein was funded through this program by a grant to the Dartmouth Toxic Metals Research Program. ${ }^{8}$ Although community outreach programs supported by the SBRP do not engage in research, many have adopted CBPR principles in working with communities to address environmental health issues. For example, CBPR principles have been found to be particularly effective in addressing environmental justice issues, such as childhood lead poisoning. ${ }^{6,9}$

CBPR principles include open communication and mutual respect for the knowledge, expertise, and resources of all partners. ${ }^{10}$ The role of trust, and the importance of recognizing that trust evolves in relationships over time, is critical to effective CBPR. ${ }^{6}$ In CBPR, the academic collaborator assumes the role of co-learner. Research is framed and implemented with community participation and with the goal of translating findings into social action and change. ${ }^{6,11}$ These norms and values played a vital role in the success of the lead poisoning prevention initiatives implemented through this academic-community collaboration. Specifically, we suggest that adaptability, consistency, shared authority, and trust are values common to CBPR and community-based partnerships.

We observe that being able to engage in collaborations that are not research driven eliminates potential conflicts for partners. Conflict between academic researchers and communities is often driven by research goals, such as theory development and/or data collection. This raises the question of whether academic partners are "doing to" or "doing with" community partners. ${ }^{12}$ Translating scientific knowledge based on community interests, and engaging in capacity building efforts grounded in evidence-based practices, helps to mitigate unproductive tensions. Applying the values of CBPR fosters a shared agenda for academic-community partnerships.

A defining attribute of this collaboration was an appreciation for the different experiences, strengths, and resources of the collective partnership. The Health Department contributed time and hands-on experience in childhood lead poisoning prevention efforts in the city. The practical advice and skills of the GMPALP provided experiential knowledge and a network of community partners. As science translators, 
the Dartmouth Group contributed time, funding, and access to current research on lead toxicology, risk communication, and best practices in lead poisoning prevention. The collaboration described in this article reflects the successful merging of these different experiences, orientations, and shared values.

\section{SELECTED PARTNERSHIP MILESTONES}

Initially, the Dartmouth Group attended meetings of the GMPALP and looked for opportunities to share scientific and best practice information. Examples include conducting focus groups about the needs for lead poisoning information among Manchester's Latino population; researching issues of interest to GMPALP members, such as establishing lead-safe housing registries; and funding training for lead abatement contractors. All of these projects supported endeavors by one or more members of the community-based GMPALP, and encouraged new working strategies among members. The cumulative effect of these efforts established the Dartmouth Group as collaborators, and assured community members that they did not intend to "take over" the community's agenda.

By 2005, a community consensus was building: Policy change was essential for progress to be made in Manchester on this issue. That year, the academic-community partners hosted a meeting, "A Call to Action: Eliminating Lead Poisoning in Manchester," which resulted in two foundations agreeing to fund a broad-based Lead Poisoning Prevention Collaborative to coordinate statewide efforts addressing lead poisoning. In 2006, the Dartmouth Group submitted a proposal to make lead poisoning prevention an "Action Step" priority for the New Hampshire Children's Advocacy Network, a coalition of nearly 200 state organizations committed to children's issues. New Hampshire Children's Advocacy Network members adopted lead poisoning prevention as a priority for the 2007 legislative session. In 2007, members of the partnership were appointed to the Governor's Task Force on Lead Poisoning Prevention, which was asked to review the state's current laws and regulations and propose changes. Key recommendations of this Task Force enabled a bill to be passed which makes state lead laws more protective of children.

Although this linear account describes selected outcomes of this academic-community partnership-capacity building, social action, and policy change-it omits the process of collaboration, which was anything but linear. The course of the Childhood Lead Screening Initiative illustrates this nonlinear path.

\section{COLLABORATORS AS CO-LEARNERS: A PRODUCTIVE TENSION}

Throughout this collaboration, the Dartmouth Group approached projects from the perspective of theory or "best practice" and valued data collection as a necessary prelude to action. In contrast, the Health Department and GMPALP approached the project from the perspective of first-hand knowledge and valued service delivery over "more study." Shared authority in the decision-making process promoted mutual respect among partners over the course of the collaboration. However, in this academic-community partnership, as is often the case in CBPR, participation and control are never static or linear. ${ }^{6}$

Participation in the Screening Initiative involved the Health Department, the Dartmouth Group, GMPALP, and five local pediatric or family practice groups that volunteered to participate. The initiative began after the participants in Manchester's "Call to Action" meeting identified "engaging health professionals to ensure that all Manchester children are screened for lead poisoning and treated as early as possible" as a priority for community action. The first goal was identifying barriers to childhood lead screening. This included a retrospective review of the medical charts of screening-aged children in the participating medical practices (conducted by the Health Department) and focus groups for each medical office to probe understandings and practices regarding childhood lead screening (conducted by the Dartmouth Group with consultation by GMPALP clinicians.)

Had the project continued as designed, the chart audits and focus group report would have been completed within a few months, and the results would have been presented to the participating practices and the GMPALP for discussion. However, personnel changes and the day-to-day crises faced by the Health Department placed formidable constraints on staff time, stalling the chart audit for several months. Meanwhile, different goals and expectations for the focus group sessions emerged, reflecting the respective pragmatic or theoretical orientations of the partners. The Manchester Health Department viewed the focus group visits as an opportunity to educate practices about their role in providing case management for lead poisoned children. 
The Dartmouth Group questioned whether this educational component might compromise the data being collected. The way this tension resolved illustrates the importance of collaborations that value evidence-based action outside of a strict research setting. It also illustrates the importance of adaptability and trust in academic-community partnerships.

The Manchester Health Department's argument that these meetings were a rare opportunity to disseminate knowledge in a face-to-face setting persuaded the Dartmouth Group to agree to abandon the strict focus group convention and allow for each session to end with an educational presentation. These "lunchtime conversations" were transcribed and analyzed as originally planned. It became clear, as the modified protocol proceeded, that practitioners had valuable insights to contribute regarding barriers to screening.

\section{PRODUCT OF AN ACADEMIC-COMMUNITY OUTREACH COLLABORATION}

The barriers to childhood lead screening identified through these lunchtime conversations are consistent with those found by other groups. ${ }^{13}$ Studies examining why physicians do not follow practice guidelines have identified barriers, such as lack of familiarity, disagreement with guidelines, lack of outcome expectancy, external barriers, and inertia of previous practice. ${ }^{14}$ The Manchester practices identified all of these barriers to childhood lead screening. However, the most striking finding from the interactions with clinical practices was that there seemed to be no consistent "systems of care" around childhood lead screening. Despite Centers for Disease Control and Prevention guidelines and screening recommendations from New Hampshire's Childhood Lead Poisoning Prevention Program, wide variation both within and across these practices existed in the timing of and criteria for screening, types of testing, and laboratory locations.

These findings confirmed the need to educate local medical providers about screening, but also pointed to a need and opportunity to help practitioners identify office systems issues within their control. Drawing on the clinical practice improvement literature, the partners designed the implementation phase of the screening initiative to include a presentation of the chart audits to the practices, along with an offer of clinical practice improvement coaching by a member of the health department, who would be trained for this purpose.
During the next phase of the project, the partners presented poster-sized charts and graphs illustrating the decline of childhood lead screening rates in Manchester compared with national rates, as well as each practice's screening rate compared to de-identified childhood lead screening data from other city practices. The visits combined the educational technique of "audit and feedback" with aspects of academic detailing, both of which have been found to be effective methods of clinical practice improvement. ${ }^{15}$ Providing specific, individualized feedback to practitioners in this informal setting stimulated a lively dialogue about lead screening, with some practitioners reporting they had already begun making changes because of the initial visit. However, as the visits to clinical practices concluded, the health department determined that training personnel to provide quality improvement coaching on lead screening for practitioners throughout the city was too time consuming to be feasible or sustainable. Once again, the partners confronted the need to adapt their plan.

After consultation with quality improvement professionals and feedback from the collaborating practitioners, the partners decided to develop an online Quality Improvement Toolkit that would serve the same function as the multiple face-to-face visits. Early versions of the online toolkit were tested by the collaborating practitioners who noted that the timing of their well-child visits did not correspond with the recommendations for lead screening at 1 and 2 years of age. This insight from community practitioners provided an opportunity for dialog about how practice patterns were affecting screening in the city, and enabled the partners to incorporate this information to produce more accurate screening rate reports. GMPALP clinician members and participating practitioners also tailored the layout and language used in the online toolkit and suggested resource materials for office staff, patients, and community neighbors. Based on this feedback, the online Quality Improvement Toolkit for Childhood Lead Screening and Management was modified to include the following components: (1) Grand Rounds-style lectures (two by GMPALP members) to educate practices about improving the quality of their childhood lead screening and management procedures; (2) a streamlined, self-administered chart audit tool that generates an immediate practice-level screening report and practice systems analysis; and (3) supplemental resources, such 
as patient brochures on lead poisoning in several languages, the New Hampshire Childhood Lead Poisoning Prevention Program's screening and management guidelines, and maps illustrating high-risk neighborhoods and communities in the Manchester area.

\section{LESSONS LEARNED}

Our findings suggest that the success of this outreach partnership is enhanced by four core values:

1. Adaptability: Change is to be anticipated in long-term partnerships, and an openness to modifications and course corrections in keeping with project goals is important for navigating unforeseen change.

2. Consistency Over Time: Academic partners are often viewed as short-term visitors who "parachute in" for research data and leave. The Dartmouth Group established a consistent presence in Manchester by working with multiple partners on childhood lead poisoning prevention and by seeking ways to ensure sustainability for projects. Although the health department experienced numerous changes, externally and internally, during the course of this collaboration, they maintained their commitment to the project.

3. Shared Authority: Collaborators brought different perspectives and experiences to the partnership and acted on the basis of shared authority and expertise; all decisions on this project were made by consensus. A productive tension among all partners was a hallmark of this process. For example, as "science translators," the Dartmouth Group provided access to scientific findings and expertise, valued study before action, and consulted the literature as a basis of understanding. As the public health and community authorities, the Health Department and GMPALP partners had clinical knowledge and experience, were familiar with the politics and history of the lead poisoning problem in the community, and understood the constraints of clinical practices.

4. Trust: A collaboration is an interactive process, not an act. Likewise, trust is a property of relationships that evolves over time, not an independent variable that can be engineered at will. All parties must be willing to take the risk of working together to achieve the established goal. ${ }^{16}$ In this case example, time invested by partners in developing a mutual understanding of roles and social identities was time well spent, because this is how trust evolved.
From the outset, it was clear to all partners that the goal of this academic-community partnership was to facilitate community change through collaboration. As Altman ${ }^{12}$ has suggested, sustainability is enhanced when academic partners are understood to be "doing with" (rather than "doing to" or "doing for") community partners. Because research was not a goal of the screening initiative, the partners were able to take a holistic rather than reductionist approach and to emphasize process, sustainability, and relationship and capacity building. This path presented few constraints to redefining both process and product throughout the course of the screening initiative, and it allowed the partners wide latitude to adjust timetables and to accommodate competing time demands. The "doing with" orientation also made it possible for partners to strike an appropriate balance between theoretical and pragmatic biases. For example, focus groups morphed into "lunchtime conversations" and initial plans for a "train the trainers" evolved into a self-administered, sustainable, online Quality Improvement Toolkit without compromising the goal.

\section{SUSTAINABILITY FOR AN ACADEMIC-COMMUNITY OUTREACH PARTNERSHIP}

Sustainability for this academic-community partnership has been a result of capacity building and an expanded web of partners. For example, two new lead paint safety workshops for homeowners and rental property owners were funded, developed, and evaluated by this partnership, and are now being offered by a contracted trainer. The City of Manchester was awarded a U.S. Department of Housing and Urban Development funding (matched by Dartmouth) and a Lead Coordinator was hired to build on successful, collaborative relationships in the city to expand educational outreach on lead. Members of this academic-community partnership have been appointed to a State Legislative Study Commission to generate recommended strategies and resources addressing lead hazards. In addition to an expanded network linking the public health community in the region with the academic community, this academic-community partnership has fostered stronger ties that continue today among the health department, the GMPALP, and the clinical practitioners that conduct lead screening and case management in the Manchester area. 
Facilitating respectful, transparent relationships is an important benchmark of a successful academic-community partnership. The trust built from investing time into this process yields social capital that offers rich returns for all partners. This case example illustrates the role of adaptability, consistency, shared authority, and trust as core values for such partnerships. It also demonstrates how the principles of CBPR, such as recognizing the unique strengths of all partners, support effective and sustainable collaborations between academia and community groups. We suggest that this partnership among an academic group, a local health department, and a broadbased community consortium is an example for other alliances between academicians and the community-professionals in traditionally separate disciplines-facing local health issues with similar barriers, complexities, and goals of building capacity and sustainability. Finally, we observe that unique funding sources, such as the Community Outreach component of the National Institute of Environmental Health Sciences SBRP, are valuable for improving public health by bringing academic groups into productive, sustainable relationships with com- munities affected by environmental health hazards. Programs such as these should be supported and encouraged.

\section{Acknowledgments}

The project described was supported by NIH Grant Number P42 ES007373 from the National Institute of Environmental Health Sciences. Its contents are solely the responsibility of the authors and do not necessarily represent the official views of the National Institutes of Health. This project benefited from the support of the Manchester Health Department in Manchester, New Hampshire; the Greater Manchester Partners Against Lead Poisoning; the New Hampshire Childhood Lead Poisoning Prevention Program; Child Health Services, Dartmouth-Hitchcock Manchester Pediatrics, Dartmouth-Hitchcock Manchester Family Practice, Manchester Community Health Center, and Hampshire Pediatrics (Manchester, NH clinical practices); Denise Anthony, PhD (Dartmouth College); Cecelia Gaffney, MPH (Dartmouth-Hitchcock Medical Center); and Kathy Mandeville, RN, MS, MPH (Manchester Health Department, Manchester, New Hampshire). 
1. City of Manchester, New Hampshire MHD. Public health report cards [cited 2008 Feb 15]. Available from: http://www .manchesternh.gov/CityGov/HLT/files/9F33CC241BAE4DF2 A0329BD5B77D8EED.pdf

2. United States Census Bureau. Population finder. [cited 2008 Feb 15] Available from: http://www.census.gov/

3. New Hampshire Childhood Lead Poisoning Prevention Program. "New Hampshire Blood Lead Surveillance Data, 2006." New Hampshire Department of Health and Human Services, Concord, NH. May 2007.

4. Caron RM, DiPentima R, Alvarado C, Alexakos P, Filiano J, Gilson T, et al. Fatal pediatric lead poisoning-New Hampshire, 2000. MMWR. 2001;50:457-9.

5. New Hampshire General Court-Legislation [cited 2008 Feb 15]. Available from: http://www.gencourt.state.nh.us/legislation/2007/SB0176.html

6. Wallerstein NB, Duran B. Using the community-based participatory research to address health disparities. Health Promot Pract. 2006;7:312-23.

7. Superfund Basic Research Program, National Institute of Environmental Health Sciences. 2006 request for applications [cited 2008 Feb 15]. Available from: http://www-apps.niehs. nih.gov/sbrp/rfa/rfa_guidelines.html

8. Dartmouth Toxic Metals Research Program, Center for Environmental Health Sciences at Dartmouth [cited 2008 Feb 15]. Available from: http://www.dartmouth.edu/ toxmetal/

9. Scammel M, Dearry A. Advancing the community-driven research agenda: A conference report. National Institute of
Environmental Health Sciences, Environmental Justice and Community-Based Prevention/Intervention Research Grantee Meeting. October 27-29, 1997, Research Triangle Park, N.C.

10. Metzler MM, Higgins DL, BeekerCG, Freudenberg N, Lantz PM, Senturia KD, et al. Addressing urban health in Detroit, New York City, and Seattle through community-based participatory research partnerships. Am J Public Health. 2003;93:803-11.

11. O'Fallon LR, Tyson F, Dearry A. Successful models of community-based participatory research-Final report. Washington, DC: National Institute of Environmental Health Sciences; 2000.

12. Altman DG. Sustaining interventions in community systems: On the relationship between researchers and communities. Health Psychol. 1995;14:526-36.

13. Alliance to End Childhood Lead Poisoning. A brief guide to options for improving Medicaid lead screening. Washington, DC: Alliance for Healthy Homes (formerly Alliance to End Childhood Lead Poisoning); 2002.

14. Cabana MD, Rand CS, Powe NR, Wu AW, Wilson MH, Abboud PAC, et al. Why don't physicians follow clinical practice guidelines? A framework for improvement. JAMA. 1999;282:1458-65.

15. Trowbridge $\mathrm{R}$, Weingarten $\mathrm{S}$. Making health care safer: A critical analysis of patient safety practices. Washington, DC: Agency for Healthcare Research and Quality, U.S. Department of Health and Human Services; 2001.

16. Mantoura P, Gendron S, Potvin L. Participatory research in public health: Creating innovative alliances for health. Health Place. 2007;13:440-51. 